\title{
Common traits associated with establishment and spread of Lessepsian fishes in the Mediterranean Sea
}

Article in Marine Biology · September 2015

DOI: $10.1007 /$ s00227-015-2744-3

CITATIONS

6

2 authors:

\section{Erik Arndt}

Hochschule Anhalt

11 PUBLICATIONS 109 CITATIONS

SEE PROFILE
Patrick Joseph Schembri

University of Malta

263 PUBLICATIONS 2,430 CITATIONS

SEE PROFILE

Some of the authors of this publication are also working on these related projects: 


\title{
Common traits associated with establishment and spread of Lessepsian fishes in the Mediterranean Sea
}

\author{
Erik Arndt ${ }^{1} \cdot$ Patrick J. Schembri $^{2}$
}

Received: 25 February 2015 / Accepted: 14 September 2015 / Published online: 24 September 2015

(C) Springer-Verlag Berlin Heidelberg 2015

\begin{abstract}
It was more than 30 years after the opening of the Suez Canal in 1869 that the first reports on Indo-Pacific fishes entering the Mediterranean Sea (so-called 'Lessepsian migration') were published. The number of new records of Lessepsian fishes remained more or less constant between 1920 and 2000 but increased dramatically after that. The accelerated rate of entry was attributed by many authors to an increase in the Mediterranean surface water temperature. However, the Suez Canal has been repeatedly deepened and widened during the last decades and the increased immigration rate of Red Sea fishes might also be related to reduced dispersal barriers. We analyse the relationship between dispersal and establishment success and a pool of different traits for 101 Lessepsian fish species using generalized linear models. Our models did not reveal a significant relationship between the sea surface temperature in the native range of immigrant fishes and their dispersal or establishment success in the Mediterranean Sea. The minimum depth in which a species was observed was
\end{abstract}

Responsible Editor: M. Peck.

Reviewed by undisclosed experts.

Electronic supplementary material The online version of this article (doi:10.1007/s00227-015-2744-3) contains supplementary material, which is available to authorized users.

Erik Arndt

e.arndt@loel.hs-anhalt.de

Patrick J. Schembri

patrick.j.schembri@um.edu.mt

1 Department 1, Anhalt University of Applied Sciences, Strenzfelder Allee 28, 06406 Bernburg, Germany

2 Department of Biology, University of Malta, Msida MSD 2080, Malta the only significant trait influencing dispersal success. This trait is likely related to the architecture of the Suez Canal since until the 1970s only species with a very low minimum depth were recorded to have entered the Mediterranean, but species occurring in deeper water started to immigrate after 1980 when the canal was deepened to $19.5 \mathrm{~m}$. The establishment success of Lessepsian fishes was significantly linked to size and spawning type. Benthic spawners and species with adhesive eggs represent successful colonizers. Moreover, successful colonizers are species with a tendency to form schools, whereas solitary species are less successful. The results show that dispersal and establishment success of Lessepsian fish immigrants are influenced by different ecological traits.

\section{Introduction}

The construction of canals bridges natural barriers to the distribution of aquatic organisms. It allows aquatic organisms to spread to new geographical areas and often results in important changes to the newly colonized ecosystems and their species assemblages (Leppäkoski et al. 2002; Gollasch et al. 2006; Nentwig 2007). This type of human mediated invasion has been frequently observed for freshwater canals. A well-known example is the Rhine-Main-Danube Canal, connecting not only the catchments of two of the largest European rivers but also the Black Sea with the North Sea. This canal caused one of the most extensive invasion processes known for freshwater systems (Tittizer et al. 2000) and resulted in severe ecological problems (Haas 2002; Leppäkoski et al. 2002; Nentwig 2007). The canals of the 'Chicago Waterway System' in North America, connecting the Great Lakes with the Mississippi catchment, had similar important impacts (Brammeier et al. 2008). 
Fig. 1 Mean annual immigration rate per decade (except for 1867-1869 and 2010-2014) of Indo-Pacific fish species, sea surface temperature (Celsius) of the Mediterranean Sea (SST) and depth of the Suez Canal (in metres) at various times

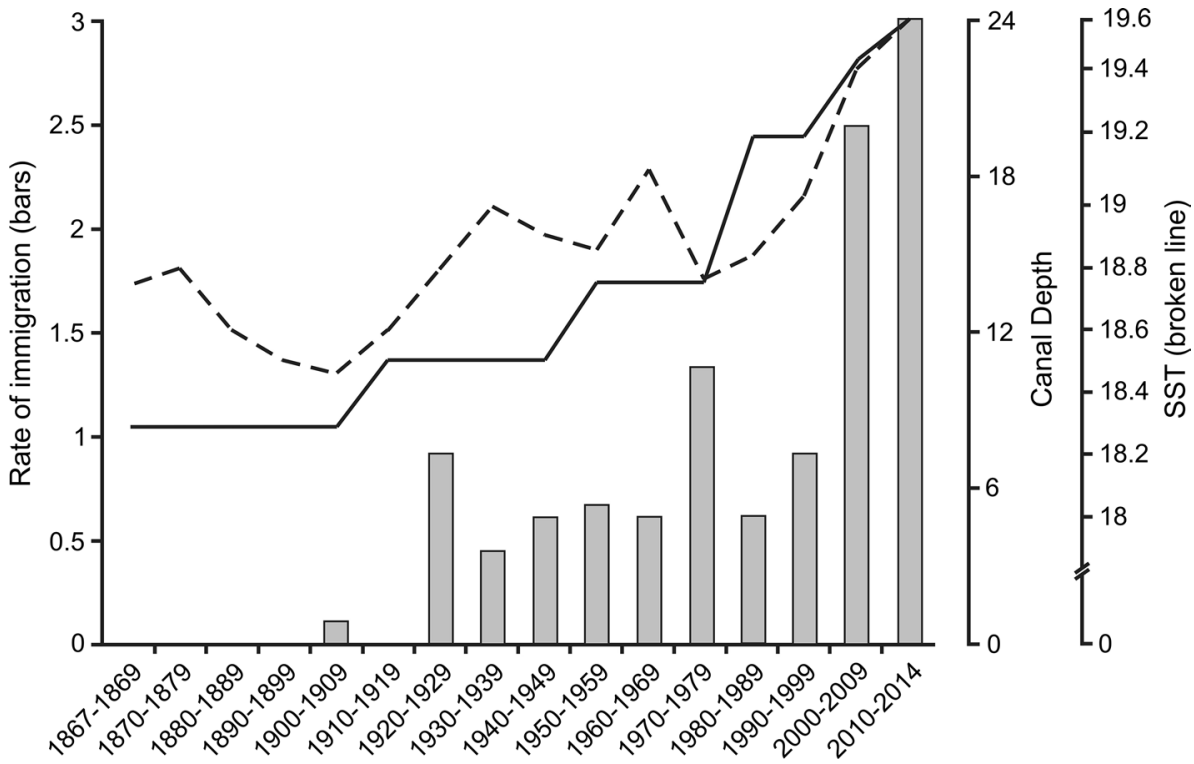

In the marine realm, beside the Panama canal, one canal in particular has been of overwhelming importance for the spread of organisms from one sea to another and thus for bringing about profound changes to the ecology of the affected ecosystems and their species: the Suez Canal (Golani 1998; Galil 2006; Rilov and Galil 2009). The importance of this canal has not only been limited to ecology and biogeography. Because several Indo-Pacific fish species that have immigrated to the Mediterranean Sea are now present at high abundances and are extensively fished, this canal has had a considerable influence on the fisheries of the region, and thus on the economy as well (Rilov and Galil 2009; EastMed 2010).

Just over 30 years from the opening of the Suez Canal in 1869, Tillier (1902) reported Atherinomorus forskalii from Alexandria (Egypt) and Liza carinata as well as other species from the vicinity of Port Said. Unfortunately the exact date of when the first fishes entered the Mediterranean is not known, but the reports by Tillier (1902) and Norman (1929) imply that these fishes could have arrived in the Mediterranean much earlier than 1902. At the time, the canal was about $8 \mathrm{~m}$ deep and the 'Bitter Lakes' that were incorporated in its route (Small Bitter Lake, Great Bitter Lake, Lake Timsah and Lake Manzala) and were still hypersaline. It was only in the 1920s after the canal was deepened to $11 \mathrm{~m}$, that a further influx of Lessepsian species was reported from the Mediterranean coasts of Israel and Egypt (Steinitz 1927; Norman 1927, 1929). With further enlargement of the canal in $1956(14.0 \mathrm{~m}), 1980(19.5 \mathrm{~m}), 2001(22.5 \mathrm{~m})$ and, most recently, in 2010 (24 m), its depth is now three times, and the bottom width five and a half times, that of the original construction (Galil 2006; Suez Canal Authority 2015). The salinity of the 'Bitter Lakes' gradually declined to approximate that of the Red Sea and the physical and physiological barriers to the entry of fish from the Gulf of Suez were largely removed such that the salinity of the canal no longer hindered successful immigration into the Mediterranean Sea (Belmaker et al. 2013). The number of Lessepsian fish species increased steadily in the decades following the 1920s but accelerated dramatically after the year 2000 (Fig. 1) and numbered 101 species in 2014 (see Table in Supplementary material).

The accelerating influx of Lessepsian fish species in the Mediterranean Sea has been the subject of several papers. Most authors invoke climate change and increasing Mediterranean water temperatures as the chief cause of the increasing numbers of non-indigenous fish species being recorded from the Mediterranean since the 1980s (Ben-Tuvia and Golani 1996; Pallaoro and Dulčić 2001; Despalatović et al. 2008). Azzurro (2008) reports a northwards shift in the distribution of 51 thermophilic fish species in the Mediterranean Sea, 11 of which are of IndoPacific origin. If the Mediterranean continues to warm at the present rate, Ben Rais Lasram and Mouillot (2009), Ben Rais Lasram et al. (2010) and Raitsos et al. (2010) expect an increasing immigration of sub-tropical and tropical Lessepsian species.

However, the accelerating number of Lessepsian immigrants is not only associated with the increasing water temperature but is also influenced by changes in the canal architecture (i.e., depth, width, profile) and the more balanced salinity relative to original conditions. Altering the architecture of the canal, and therefore altering also the current patterns, may enable the immigration and dispersal of species which were not able to overcome the barriers presented by the canal in the past. Therefore, temperature 
preference is not the only or even the most important factor for the success of Lessepsian fish species.

Trait-based approaches allow a more detailed evaluation of the characteristics of immigrating fish species, especially if they consider not only one species or a species group but all available information. Up to now, only a couple of studies including data on all Lessepsian species have been published. Golani (1993) focussed on habitat-related traits of Red Sea fishes and concluded that dominance in the equivalent source habitat is a key contributor to successful colonization of the Eastern Mediterranean. Ben Rais Lasram et al. (2008) examined several ecological characters of Lessepsian fish species such as "climate match", position in the water column, propagules, maximum length, "confamilial resistance" (i.e. invading species without or with few confamilial counterparts in the Mediterranean Sea should have a higher dispersal success rate than species which encounter many close relatives), and year of first record, with regard to dispersal success of the species. These authors concluded that only the "climate match" and the year of first record correlated significantly with dispersal success, thus confirming the crucial importance of temperature.

However, Belmaker et al. (2013) challenged the opinion that increasing immigration rates are due to increasing Mediterranean sea surface temperatures (SST) and even the overall importance of climate change for Lessepsian fish immigrations. Belmaker et al. (2013) compared parameters of the distribution range and preferred SST of all Red Sea fishes with those of Lessepsian immigrants only. The authors recognized a significant higher maximum SST in Lessepsian fishes compared with the whole Red Sea species pool, comprising both Lessepsian and non-Lessepsian species. In effect, what these authors are suggesting is that an increase in Mediterranean SST may hinder the establishment of some potential Erythraean immigrant species due to their inability to tolerate the higher southern Mediterranean summer SST relative to the conditions in their native range (Belmaker et al. 2013: 5).

The aim of the present study is to present a more detailed analysis of the traits of Lessepsian species. We test if particular traits of non-indigenous fish species are related with dispersal and/or the establishment success in the Mediterranean Sea. For this purpose we differentiate between the characters 'dispersal' (as a function of spread) and 'establishment' (as a function of abundance or population size). Besides temperature data in the species' native range, range dimension, habitat and feeding type, we included behavioural and developmental characters of the species in the analysis, such as schooling, spawning and larval characters. The investigation of these characters may help to better explain the success of establishment and dispersal of Lessepsian fishes in the Mediterranean Sea.

\section{Materials and methods}

All 101 Lessepsian fish species reported until October 2014 were included in the analysis (see Table in Supplementary material). Sources for this data set are Golani and Appelbaum-Golani (2010a) and references cited therein as the fundamental database, and additionally Akamca et al. 2011; Bariche 2010a, b, 2011, 2012; Bariche and Azzurro 2012; Bariche and Heemstra 2012; Bariche et al. 2013; Bilecenoğlu 2012; Çiçek and Bilecenoğlu 2009; Dalyan et al. 2012; Fricke et al. 2012; Golani and AppelbaumGolani 2010b; Golani et al. 2010, 2011; Goren et al. 2010a, b, 2011; Özgür Özbek et al. 2014; Özvarol and Gökoğlu 2012; Salameh et al. 2010, 2011, 2012; Stern and Goren 2013. A bibliography of records of these Lessepsian species in the Mediterranean Sea was compiled to analyse the two aspects of invasion success: dispersal and establishment. For each species the most important references indicating the progress of dispersal are given in the Supplementary material.

The traits of the Lessepsian immigrants were compiled from the databank FishBase (Froese and Pauly 2014), the CIESM Atlas of Exotic Species in the Mediterranean (Golani et al. 2013) and an additional 89 references (see list in Supplementary material). Froese and Pauly (2014) and data from OBIS (2015) were used to determine the distribution of species. The World Ocean Atlas database (Locarnini et al. 2013) was used to obtain the minimum sea surface temperature (SST), maximum SST and the SST range of the native distribution area of all fish species considered.

\section{Dispersal and establishment success}

\section{Dispersal success}

This parameter describes the distance travelled of the Lessepsian species. We use three ordinal categories: (1) Low dispersal success; records only in one locality or region near the entrance of the Suez Canal. (2) Medium dispersal success; records from the coast from Lebanon to South Turkey and Rhodes or Egypt west of Alexandria but not west of Rhodes or the Egypt-Libya boundary, respectively. (3) High dispersal success; migration to the Central and/or Western Mediterranean Sea beyond the boundaries of the Levantine Sea.

\section{Establishment success}

The 'establishment success' is a surrogate of abundance or population size. A successful establishment is not necessarily related to the dispersal ability. On the one hand, large abundances, even dominating fishery catches, can be achieved in 
a restricted area, e.g., the Israeli and/or the Lebanon coasts. On the other hand, a species may travel as far as the Central Mediterranean Sea but is recorded only as single individuals. Analogous to the dispersal success, we use three ordinal categories for the establishment success: (1) Low; only solitary individuals have been recorded. (2) Medium; repeated records up to 50 individuals. (3) High, large numbers, at least locally dominant in fishery trawls [ $>1 \%$ of total catch] or frequent sightings of small numbers of the species (not singletons) in many different Mediterranean localities.

\section{Geographical distribution and area-related temperature parameters}

The North-South extension (latitudinal range) as well as the East-West extension (longitudinal range) of the native distributional area of each species was estimated and calculated as the maximum linear distance in kilometres. Subsequently the minimum SST, maximum SST and the SST range of the distributional area were determined. The SST range is the difference between the maximum and minimum SST in the native distributional area of the species. All five parameters are interval-scaled variables.

Historical SST data from the Mediterranean Sea were obtained from Ben Rais Lasram and Mouillot (2009) and Mariotti et al. (2015).

\section{Ecological traits}

\section{Depth range}

Two different parameters: the minimum and maximum depth, in metres, in which a species was observed, were calculated separately.

\section{Habitat type and use}

Six nominal categories: (1) Pelagic. (2) Hard bottom, rocks, caves, crevices. (3) Soft bottom. (4) Vegetated bottom including seagrass meadows and algal forests. (5) Multi habitat use; rocks and soft bottoms, seagrass meadows etc.; often benthopelagic species. (6) Bathyal habitats.

\section{Feeding type}

Five nominal categories: (1) Predator. (2) Grazer/browser. (3) Plankton feeder. (4) Generalist feeder. (5) Specialist feeder, i.e., feeding on sponges or corals.

\section{Body size}

Several morphological characters of species have been used as surrogates of life history traits, e.g., characters of head and mouth related to food or feeding behaviour. The body size is the only morphological character used here. The common or maximum body size is related to the dispersal ability, the average fecundity, and maximum lifespan (Kolar and Lodge 2002; Marchetti et al. 2004). A large and long-lived species may be able to migrate over a longer distance. On the other hand, invasion success was attributed to species with small adult size that are characterized by rapid growth, early maturity and high fecundity (Moyle and Marchetti 2006; Ben Rais Lasram et al. 2008). The common length $[\mathrm{cm}]$ as defined by Froese and Pauly (2014) was used here.

\section{Schooling level}

Four ordinal categories: (1) Solitary individuals. (2) Occurring mostly in pairs. (3) Usually forming small groups (3-50 individuals). (4) Usually in large schools (>50 individuals).

\section{Spawning and brood care behaviour}

Four nominal categories: (1) Pelagic spawner. (2) Benthic spawner. (3) Parental care behaviour, mouth brooders or benthic with nests in which eggs are guarded. (4) Other spawning types or behaviour, in particular adhesive eggs (on flotsam, sometime on the bottom) or viviparous.

\section{Larval type}

Three nominal categories: (1) Pelagic/planktonic larvae. (2) Benthic or benthopelagic larvae. (3) Other larval mode of life, e.g., attached to floating debris.

\section{Diel activity}

The main activity period is an important ecological trait and was included in models by Belmaker et al. (2013). However, exact or verifiable data on activity were not available for all species considered here. Moreover, different activities such as feeding, migratory behaviour or spawning, may possibly occur at different periods of the day. Therefore the data in the table of Supplementary material must be considered as tentative. Owing to this the diel activity was not included in the GLM but was used to test the significance of differences in dispersal success, establishment success and minimum depth between diurnal and nocturnal species. Four nominal categories were distinguished: (1) Diurnal. (2) Nocturnal. (3) Not specified, active during day and night. (4) Species restricted to deep water with unknown or undetermined activity patterns. The specification refers to adult stage if adults and juveniles differ in diel activity (for example, as in Plotosus lineatus). 


\section{Year of first record}

We included the year of first record in our calculation (see "Statistical analysis" for more information) in order to compare our results with previous studies that have considered this parameter (see the Discussion).

The parameter was calculated as $\mathrm{x}-1901$, with $\mathrm{x}=$ year of first record. Thus the year of the first published record of a Red Sea species in the Mediterranean Sea (1902) is listed as 1 in the database and the year 2014 as 113 .

\section{Statistical analyses}

A generalized linear model (GLM) was used to explore species traits influencing significantly the success of dispersal and establishment. The Poisson distribution (log link function) was selected (see McCullagh and Nelder 1989; González-Irusta et al. 2012 for further information about this model and distribution type). The model computation was carried out twice, using dispersal success and establishment success as the dependent parameter, respectively. Eight parameters (traits) were included in the analyses (cf. Tables 1,2). The GLMs were also calculated including the independent parameter 'year of first record' as an additional ninth parameter. A separate model including the 'year of first record' was also used because the time lag is not an intrinsic ecological character but may have influence on the increase in populations or the extent of spread.

Before calculation of the GLM, a factor analysis (varimax rotation, 5 iterations) was carried out in order to reduce the number of metric parameters. Two main components were extracted by the factor analysis, indicating a high dependence between (a) minimum and maximum depth in which a species was observed, and (b) between latitudinal range, longitudinal range, minimum and maximum SST of the species' native distribution areas, and SST range of the species' native distribution areas. The parameters minimum depth and SST range had the highest load in their component group and were selected for the GLM. The analysis was repeated with 'minimum SST' instead of 'SST range' with the same result. The trait diel activity was excluded from the GLM calculation as explained above.

Spearman's rank correlation coefficient was used for pairwise correlation of metric or ordinal data sets and the Mann-Whitney U-test or the Kruskal-Wallis oneway analysis of variance by ranks were used to estimate whether two or more non-normally distributed samples originate from the same distribution. All calculations were done using the IBM SPSS (version 22) program suite.

\section{Results}

Data for 101 fish species (99 Teleostei and 2 Elasmobranchia) were included in the analyses. Of these species, 21 have a low dispersal success, i.e. they are only known from Egypt or Israel. A medium dispersal success was found for 41 and a high success for 39 species. Considering decades separately, most species with high dispersal success were first recorded between 2000 and 2009. Fistularia commersonii and Lagocephalus sceleratus are actually the most widespread Lessepsian fish species.

The establishment success was low for 40 , medium for 29, and high for 32 Lessepsian species. Despite the fact that different traits could influence dispersal or establishment success, both parameters were correlated (Spearman's Rho, $\left.r_{\mathrm{S}}=0.651 * * *\right)$.

\section{Traits affecting dispersal success}

The exploration of species traits using a generalized linear model yielded only the minimum depth in which a species was observed as influencing the dispersal success significantly ( $p=0.024$, Table 1$)$. The minimum depth was significant, independently of including the year of first record in the calculation or not (the result of the calculation including the year of first record is not shown in Table 1).

Inspection of the species' minimum depths in the different levels of dispersal success revealed a mean minimum depth of $22.2 \mathrm{~m}$ for the low, $14.2 \mathrm{~m}$ for the medium, and $8.0 \mathrm{~m}$ for the high dispersal success categories, respectively. The minimum depth in which a species was observed seems to be related to the stage of canal extension. The deepening

Table 1 Results of the generalized linear model for the effect of species traits of Lessepsian fish immigrants on the dispersal success of the species

\begin{tabular}{lcrl}
\hline Source & Likelihood Ratio Chi-square & $F$ & Sig. \\
\hline (Intercept) & 17.323 & 17.323 & $<0.0001$ \\
Habitat type & 5.099 & 1.020 & 0.404 \\
Feeding type & 3.368 & 0.842 & 0.498 \\
Schooling level & 6.782 & 2.261 & 0.079 \\
Spawning & 6.372 & 2.124 & 0.095 \\
Larval type & 0.327 & 0.163 & 0.849 \\
Minimum DR & 5.130 & 5.130 & 0.024 \\
Body size & 0.037 & 0.037 & 0.848 \\
SST range & 0.194 & 0.194 & 0.660 \\
\hline
\end{tabular}

Deviance of null model $=20.852 . D R$ depth range, $S S T$ sea surface temperature 
Table 2 Results of the generalized linear model for the effect of species traits of Lessepsian fish immigrants on the establishment success of the species

\begin{tabular}{llll}
\hline Source & Likelihood Ratio Chi-square & $F$ & Sig. \\
\hline (Intercept) & 2.445 & 2.445 & 0.122 \\
Habitat type & 1.393 & 0.279 & 0.924 \\
Feeding type & 4.728 & 1.182 & 0.325 \\
Schooling level & 7.542 & 2.514 & 0.064 \\
Spawning & 8.286 & 2.762 & 0.047 \\
Larval type & 0.798 & 0.399 & 0.672 \\
Minimum DR & 0.061 & 0.061 & 0.805 \\
Body size & 5.279 & 5.279 & 0.024 \\
SST range & 3.120 & 3.120 & 0.081 \\
\hline
\end{tabular}

Deviance of null model $=25.497 . D R$ depth range, $S S T$ sea surface temperature

of the Suez Canal to $19.5 \mathrm{~m}$, completed in the year 1980, seems to be particularly important: the average mean depth of Lessepsian species recorded before 1980 is $5.8 \mathrm{~m}$ ( $n=46, \mathrm{SD}=9.1$ ), but it is $19.9 \mathrm{~m}$ for species immigrating after $1980(n=55, \mathrm{SD}=53.8)$. The Mann-Whitney U-test did not show these two data sets to be significantly different.

No statistically significant influence of either minimum SST (not given in Table 1) or the range of SST on the dispersal success was found.

\section{Traits affecting establishment success}

Analogous to the analysis of dispersal success, a generalized linear model was computed to determine traits influencing the establishment success of Lessepsian fishes. The 'common length' of the fish species showed the highest significance (Table 2). The 'common length' had a mean of $44.2 \mathrm{~cm}(n=40 ;$ SD 38.8$)$ for the low establishment success fish but was $29.4 \mathrm{~cm}(n=29$; SD 32.0$)$ and $29.8 \mathrm{~cm}$ $(n=32 ;$ SD 26.0) in medium and high success fish, respectively, representing a significant difference (Mann-Whitney U-test).

Additionally, a significant effect was also found for the spawning type $(p=0.047)$. Benthic spawners and species with adhesive eggs represent successful colonizers, whereas the portion of pelagic spawners decreases with increasing establishment success (see Table in Supplementary material). Successful colonizers have a tendency to form schools, whereas the portion of solitary species decreases (from 44 to $21 \%$ ) with increasing establishment success, although these differences do not exhibit a statistical significance $(p=0.064)$.

As in the GLM analysis of dispersal success, the SST range and the minimum SST (not given in Table 2) did not significantly influence the establishment success.

\section{Discussion}

\section{Role of sea surface temperature in Lessepsian immigrations}

Temperature preference is one of the most important ecological traits and without doubt, one of the factors determining the distribution of species. There are plenty of examples that increasing SST results in a polewards spread or shift in the distribution of fishes (e.g., Roessig et al. 2004; Perry et al. 2005; Figueira and Booth 2010; Pörtner and Peck 2010). Azzurro (2008) as well as OcchipintiAmbrogi and Galil (2010) documented the temperature related shift of species, both native and non-indigenous, in the Mediterranean Sea. Ben Rais Lasram and Mouillot (2009) and Albouy et al. (2013) developed models describing changes in fish assemblages in the Mediterranean Sea due to increasing SST. In addition, long-term observations of populations suggest distinctly higher abundances of Lessepsian fish in years with high SST (Ben-Yami and Glaser 1974; Rilov and Galil 2009).

In the opinion of many authors, temperature is also the most important factor in determining the dispersal of Lessepsian fish (Ben-Tuvia and Golani 1996; Despalatović et al. 2008; Ben Rais Lasram et al. 2008; Raitsos et al. 2010). Ben Rais Lasram et al. (2008) found that subtropical Lessepsian fishes tend to spread more widely in the Mediterranean than tropical ones and that the spread could be directly related to the increase in sea surface temperatures. However, the results by Belmaker et al. (2013) do not fit this hypothesis. In the latter study, Lessepsian immigrants showed preference for higher temperatures than the average of Red Sea species. If the SST in the Mediterranean Sea would be the main factor for invasion success, Lessepsian immigrants would be expected to have lower or at least the same temperature tolerances as the mean for Red Sea species. Our results do not reveal any correlation between SST and invasion success and thus support the findings by Belmaker et al. (2013). Moreover, the invasion success of several of the most recent invaders cannot be explained by the increasing SST. For example, Fistularia commersonii, which was first recorded in the Mediterranean Sea in the year 2000, became established in most parts of the sea, including colder areas such as the Adriatic and the coasts of Spain and France, within only 8 years. This fish has colonized a new area with mean surface temperatures between $16-22{ }^{\circ} \mathrm{C}$, which is much lower than in the Red Sea, within an extremely short period. The history of the invasion of the Mediterranean Sea by F. commersonii suggests a very fast-spreading process after overcoming a dispersal barrier (the Suez Canal) independent of the SST in the new area. The fast spread of species like F. commersonii contradicts an overarching importance of SST. 
F. commersonii is one example which shows that dispersal and establishment of Lessepsian species are more complex processes than a direct result of climate change or sea warming. Lagocephalus sceleratus is a similar dramatic example, spreading between 2003 and 2014 along the southern and northern Mediterranean coasts as far as Algeria and Spain. There have been similarly fast-spreading species in previous decades (Pteragogus pelycus and Pempheris rhomboidea) as well as in the early phases of the Mediterranean invasion by Lessepsian species (Equulites klunzingeri, Siganus rivulatus and Upeneus moluccensis). Moreover, the invasion rate in the 1970s lies far above the mean value for the period 1920-2000; however, the 1970s represented a decade with a distinct SST decrease (Fig. 1). Therefore, it is clear that adaptation to temperature is only one aspect in Lessepsian immigration and that there might be other parameters with a high influence on the immigration of Red Sea species through the Suez Canal. These factors could be traits allowing passage through the canal or the successful establishment in the new environment regardless of temperature preferences.

\section{Traits supporting dispersal}

The dispersal success of fish species is linked to their ability to swim over large distances in the adult stage or to the possession of long-lived larval stages which allow the developing young to be transported by currents over large distances. The close connection between dispersal potential of marine fishes and the length of the larval phase has been confirmed by several studies (Wellington and Victor 1989; Lester and Ruttenberg 2005; Strona et al. 2012).

Adult dispersal or swimming capability has been far less intensively investigated. We know that pelagic species have a much higher dispersal capability than inshore fish (Mora and Robertson 2005; Macpherson et al. 2009). This relationship is also reflected in Lessepsian immigrants. The data set of Lessepsian species contains 18 pelagic species, 12 of which have a high dispersal success $(66.67 \%)$. Examples are Tylosurus crocodilus, Champsodon nudivittis, Scomberomorus commerson and two Sphyraena species. Benthic littoral species comprise only $26.9 \%$ of the fish with successful dispersal. The character 'pelagic' was included in the habitat type in the present study, but habitat type was not significantly correlated with dispersal success in the GLM model (cf. Table 1).

Fishes with high mobility and excellent swimming ability in the adult stage are likely to have a comparably large home range. Belmaker et al. (2013) found large home ranges to be a strong predictor for Lessepsian introductions and concluded that the passage through the Suez Canal is mostly accomplished by active adult swimming instead of passive drifting by larvae. Similar relationships have been found in freshwater invasions. Moyle and Marchetti (2006) specified a rapid dispersal of postlarval life stages and a long life span as good predictors of the fishes' ability to spread following establishment.

Ben Rais Lasram et al. (2008) found a significant connection between dispersal success and "climate match", i.e. "subtropical species" from the Red Sea had an advantage in dispersal compared to "tropical species." In our model we included the range of SST and the minimum SST in the native area of distribution of Lessepsian fish species rather than the characters "subtropical" or "tropical" because the FishBase databank does not give the criteria used for assigning species to these two biogeographical categories; the SST parameters used by us are more objective. Neither the range of STT nor the minimum SST showed a relation to the dispersal success in our model.

The only significant trait linked to dispersal success in our model is the minimum depth in which a species was observed. The relationship between minimum depth and dispersal success is not easy to explain; therefore, an indirect connection of these parameters is likely. Firstly, the factor 'time' could play a role. On the one hand, the dispersal success is closely linked to the year of first record; on the other hand, the minimum depth in which a species was observed seems to be related to the depth of the Suez Canal at the time of invasion. The canal seems to have served as a dispersal barrier for fishes preferring deeper water for many decades. As a consequence, early invaders immigrating before 1980 with preferences for shallow water habitats had more time to disperse over large distances in the Mediterranean Sea than immigrants of the last decades.

Additionally, a close relationship between the minimum depth of the immigrating species and their dispersal success could be supported by other different factors such as spawning type, schooling behaviour or habitat type. Some of these parameters show a relationship to depth range as well as to dispersal; for example, all Lessepsian species with adhesive eggs that normally attach to flotsam and species with parental care have a very low minimum depth. The former species show a high, and the latter a medium, dispersal success. Solitary species live in deeper water and have a lower dispersal success on average; in species occurring in large groups (schooling types 3 and 4), we find the opposite relationship. Considering the habitat type, species inhabiting vegetated bottoms have the lowest mean minimum depth but medium to high dispersal success (see Table in Supplementary material).

Finally, dispersal success could also be linked directly to human activities such as shipping, (i.e. to transport in sea chests or ballast water) or to aquarium release. These factors were discussed in connection with the Lessepsian immigrants Epinephelus malabaricus (Schembri and Tonna 2011), Synagrops japonicas (Orsi Relini 1990), Monotaxis 
grandoculis, Platax teira (Bilecenoğlu 2010), Pomacanthus imperator, Iniistius pavo (Golani et al. 2010), Parablennius thysanius (Özgür Özbek et al. 2014), Omobranchus punctatus (Golani 2004) and Vanderhorstia mertensi (Bilecenoğlu et al. 2008). However, the verification of shipping or the aquarium trade as introduction vectors is difficult. All of these species occur in the Red Sea and with the exception of $O$. punctatus, an autonomous immigration of the species via the Suez Canal seems to be quite possible.

Shipping as a vector for introduction of exotic fish into the Mediterranean Sea was also proposed for two further Indo-Pacific species which do not occur in the Red Sea. The first species, Oplegnathus fasciatus, is distributed from Japan and Taiwan to Hawaii. Two specimens of $O$. fasciatus were recorded in different Maltese harbours; therefore, transport via shipping from the Pacific to the central Mediterranean is a probable explanation for these findings (Schembri et al. 2010). The second example is Scatophagus argus, an Indo-Pacific brackish water species forming a small population on the south-eastern coast of Malta (Zammit and Schembri 2011). Because S. argus is offered as an aquarium fish in Malta and no other occurrence is known in the Mediterranean Sea so far, Zammit and Schembri (2011) supposed aquarium release for $S$. argus. Both $O$. fasciatus and $S$. argus were excluded from the data set evaluated here.

\section{Traits supporting establishment}

A complex of parameters and interspecific interactions are necessary for establishment of species in a new environment. From the ecological point of view, successful establishment is linked to resource use, occupation of vacant niches or successful competition, together with the ability to achieve a stable and/or large population. The r-selected life history strategy and a high genetic variability for rapid adaptation to environmental conditions are also generally accepted as prerequisites for a successful establishment of invaders in aquatic ecosystems (Safriel and Ritte 1980; Moyle and Marchetti 2006). However, there are several Lessepsian immigrants which do not follow a predominantly r-selected strategy. Representatives of 13 families have adhesive eggs (e.g., on flotsam), show different types of parental care or are ovoviviparous. Stephanolepis diaspros (Monocanthidae) and several cardinalfishes (Apogonidae) are examples of egg guarding or mouth breeding species with a high establishment success.

The genetic variability is currently still unknown for most Lessepsian immigrants but species with high genetic variability predominate in the examined cases (Hassan et al. 2003; Hassan and Bonhomme 2005; Azzurro et al. 2006; Golani et al. 2007; Bariche and Bernardi 2009) although genetic bottlenecks in successful invaders have also been demonstrated (e.g., in Saurida undosquamis by Yağlığ lu and Turan 2012, and in $F$. commersonii by Golani et al. 2007).

Golani $(1998,2010)$ summarized the characteristics of successful Lessepsian immigrant fishes and found that habitat requirements (use of sandy and muddy substrata as habitat), food supply (i.e. the pre-adaptation to an appropriate food resource) and schooling behaviour, are important parameters for successful establishment. Habitat requirements were also stressed by Rilov and Galil (2009), who found that most Lessepsian fishes are shallow water benthic predators and concluded that this is also true for the Red Sea species as a whole.

In addition to the above mentioned characters, Golani (2010) and Otero et al. (2013) considered nocturnal species of Indo-Pacific origin as successful colonizers in the Mediterranean Sea. Nocturnal feeding activity was regarded as a trait favouring low competition by native species and thus allowing access to unsaturated niches in the Mediterranean Sea. There are several examples of Lessepsian species with nocturnal activity (Golani 2010; Otero et al. 2013; Table in Supplementary material), but the conclusion that these species are particularly successful colonizers may be based on a non-representative sample. In our dataset, establishment success did not differ significantly between diurnal and nocturnal species. There are 20 nocturnal Lessepsian fish, eight of which have low, five medium and seven a high establishment success; there are several early as well as late immigrants in all three groups.

With the increasing number of Lessepsian species and more details available about their life history and the invasion process, it is now possible to search for the most important traits that affect the invasion processes, using statistical models. Belmaker et al. (2013) compared the traits of Lessepsian immigrants with those of all Red Sea species and found that Lessepsian immigrants have a larger range of environments in their native distribution area, have a larger range size and represent a higher average number of schooling species compared with all Red Sea fishes.

This complexity is also reflected by the results of our model (Table 2). Although based on a different data set and approach, our GLM supports the results of Belmaker et al. (2013) regarding the traits body size, SST and, to a certain degree, schooling behaviour. Schooling species have a significant higher probability of successful establishment than species that occur as single individuals or in pairs according to Belmaker et al. (2013). Although the schooling level was not significant in our model, shoaling or schooling fishes represent only $44.5 \%$ of Lessepsian species in the data set but $77.7 \%$ of species with high establishment success (cf. Table in Supplementary material). 
The positive relationship between body length of fishes and establishment success is more difficult to interpret. The body length strongly influences the range size and thus the dispersal and establishment ability, according to Strona et al. (2012). The range size (i.e. the maximum latitudinal and longitudinal distance in kilometres) was not significantly related to the establishment success in our model, but if range size and body length are closely linked, the body length could be the trait underlying the range size. Our model did not reveal a significant connection between the SST range or the minimum SST in the native distributional area of the Lessepsian immigrants, and their establishment success in the Mediterranean Sea, in agreement with the results of Belmaker et al. (2013).

The significance of spawning type with respect to the establishment success (Table 2) supports the conclusion by Dawson et al. (2006) that a reduced dispersal ability may favour the establishment of new populations. This phenomenon is also known from fresh water: $64 \%$ of successful fish invaders in California showed parental care, suggesting that limited dispersal of early life history stages is advantageous for invasions (Moyle and Marchetti 2006).

An appropriate food resource may support the establishment of species as demonstrated by Siganus luridus and $S$. rivulatus. These herbivorous (macrograzer) rabbitfishes belong to the set of early invaders with a wide dispersal and locally temporally extremely fluctuating populations. Their success was attributed to a low number of native Mediterranean herbivorous macrograzers and thus the rabbitfishes' occupation of an underexploited niche (Lundberg and Golani 1995). Azzurro et al. (2007) and Verges et al. (2014) confirm the niche hypothesis with detailed investigations on diet composition of both invasive Siganus species as well as the native Mediterranean herbivorous fishes Sarpa salpa and Sparisoma cretense. A resource partitioning occurs between these species through the consumption of seagrass (Posidonia oceanica), erect macroalgae and the epilithic algal matrix at different levels. Only Siganus luridus and Sarpa salpa show a wide overlap in food components (Verges et al. 2014), but do not or hardly co-occur in many geographical locations. There are two further herbivorous Lessepsian species, Scarus ghobban and Hemiramphus far and both also show high establishment success (see Table in Supplementary material) although S. ghobban was only recorded for the first time from the Mediterranean Sea in 2001. However, the food resource or feeding type of Red Sea immigrants failed significance in the GLM presented here. The majority of Lessepsian species are predaceous or planktivorous and do not show any distinct relationship of feeding mode to the establishment success.

\section{Conclusion and future prospects}

The phenomena of 'dispersal' and 'establishment' are usually regarded as intimately linked since for many species, individuals will disperse from source populations and establish new populations once the source populations are sufficiently large that there is a high continuous propagule pressure (Occhipinti-Ambrogi 2007). However, while acknowledging that these two phenomena are closely associated, in the present work we have analysed them separately since in our opinion, the successful establishment of fishes may be unconnected to their dispersal ability.

Certain species can achieve large local abundances, even if they fail to spread over large areas. Reduced dispersal ability may even favour the establishment of populations, i.e. successful establishment, after a rare accidental colonization (Dawson et al. 2006).

Establishment and dispersal success of Lessepsian fishes are closely correlated in the data set analysed here. The use of three ordinal classes (low, medium or high) to classify both phenomena constitutes a rather high level of abstraction. Although differing in 36 species only, establishment and dispersal success were supported by different ecological traits, indicating that 'invasion success' as a whole is an extremely complex subject and worthy of more detailed study. The body size is one character reflecting this complexity. A small body size is a predictor of establishment success in our model; the average standard length of species with high establishment success is $29.8 \mathrm{~cm}$. On the other hand, a large body size is often connected with highadult-swimming ability. Lessepsian fishes with high dispersal but low establishment success have an average standard length of $75.3 \mathrm{~cm}$.

Our results show that temperature related traits do not seem to be the most important parameters affecting dispersal and establishment success. The gradual increase in immigration rate of fishes is likely to be linked to the periodic deepening and widening of the Suez Canal (Fig. 1) although verification of this hypothesis is only indirectly possible via the traits of Lessepsian species. The role of the Suez Canal architecture for migrating fishes and the canal itself as a habitat should be examined carefully in future studies. This is all the more important since the Egyptian government has announced the construction of a second channel of the Suez Canal (Galil et al. 2015).

Successful establishment depends on several traits and is obviously a very complex process. Belmaker et al. (2013) point out that multiple vacant niches in the Mediterranean and a different set of trait combinations may cause the observed patterns. The same authors consider the stochastic nature of immigration and possible shifts in trait values (i.e. deviation from the mean) of Lessepsian immigrants 
because of 'environmental' filters in the new Mediterranean habitats.

Moreover, competition between native and immigrant fishes will play a role. There are signs that successful adaptive feeding and spawning strategies of the native small pelagic fish (e.g., Sardinella aurita) constrict the dispersal success of Lessepsian small pelagic fishes (Gücü et al. 2010). Competition with native fishes resulting in declining native stocks is assumed in the case of the Red Sea species Atherinomorus forskalii, Alepes djedaba, Plotosus lineatus and invasive herbivores (Goren and Galil 2005; Edelist et al. 2012; Otero et al. 2013). Many similar examples are known from European and North American fresh water systems (Mills et al. 1993; Leppäkoski et al. 2002). Successive immigrants may interact and interfere with each other, leading to a lower establishment success of the later immigrants due to competition. These interactions are difficult to observe and to verify, but more detailed and powerful models could demonstrate such interferences in the future.

Finally, the Suez Canal itself and its architecture are not the only human influences on invasion success. Even more important might be the effect of the Mediterranean fisheries that have depleted populations and changed the structure of native species assemblages and of their interactions. There are many examples from other marine regions of how community structure has been disturbed, food nets have been altered and new vacant niches created due to human activities (Jennings and Kaiser 1998; Jennings et al. 2001; Baum and Worm 2009; Tittensor et al. 2009). It is one of the more important tasks of future studies to tease out and determine the role that fisheries have played in the invasion process of Lessepsian fishes.

Acknowledgments We thank all colleagues who provided useful information about traits of species, supporting our work in this way. We are grateful to Jana Schlaugat (Bernburg) who assisted with preparation of the databank and to Helke Gröger-Arndt who prepared the figure. We acknowledge the help of Harald Grunert and Hannes Schlegel (Anhalt University) with the statistical analyses. The constructive suggestions of two anonymous reviewers improved an earlier draft of this paper. PJS was partly funded through the European Community's Seventh Framework Programme (FP7/2007-2013) under Grant Agreement No. 287844 for the project 'Towards COast to COast NETworks of marine protected areas (from the shore to the high and deep sea), coupled with sea-based wind energy potential' (COCONET).

\section{Compliance with ethical standards}

Conflict of interest The authors declare that they have no conflict of interest.

Human and animal rights This article does not contain any studies with human participants or animals performed by any of the authors.

\section{References}

Akamca E, Mavruk S, Ozyurt CE, Kiyaga VB (2011) First record of the Indo-Pacific burrowing goby Trypauchen vagina (Bloch and Schneider, 1801) in the North-Eastern Mediterranean Sea. Aquat Invasions 6(Suppl 1):19-21

Albouy C, Guilhaumon F, Leprieur F, Ben Rais Lasram F, Somot S, Aznar R, Velez L, Le Loc'h F, Mouillot D (2013) Projected climate change and the changing biogeography of coastal Mediterranean fishes. J Biogeogr 40:534-547

Azzurro E (2008) The advance of thermophilic fishes in the Mediterranean Sea: overview and methodological questions. In: Briand F (ed) Climate warming and related changes in Mediterranean marine biota. CIESM Workshop Monographs, No 35, Monaco, pp 39-46

Azzurro E, Golani D, Bucciarelli G, Bernardi G (2006) Genetics of the early stage of invasion of the Lessepsian rabbitfish Siganus luridus. J Exp Mar Biol Ecol 333:190-201

Azzurro E, Fanelli E, Mostarda E, Catra M, Andaloro F (2007) Resource partitioning among early colonizing Siganus luridus and native herbivorous fish in the Mediterranean: an integrated study based on gut-content analysis and stable isotope signatures. J Mar Biol Assoc UK 87:991-998

Bariche M (2010a) Champsodon vorax (Teleostei: Champsodontidae), a new alien fish in the Mediterranean. Aqua Int J Ichthyol 16:197-200

Bariche M (2010b) First record of the angelfish Pomacanthus maculosus (Teleostei: Pomacanthidae) in the Mediterranean. Aqua Int J Ichthyol 16:31-33

Bariche M (2011) First record of the cube boxfish Ostracion cubicus (Ostraciidae) and additional records of Champsodon vorax (Champsodontidae) from the Mediterranean. Aqua Int J Ichthyol 17:181-184

Bariche M (2012) Recent evidence on the presence of Heniochus intermedius (Teleostei: Chaetodontidae) and Platycephalus indicus (Teleostei: Platycephalidae) in the Mediterranean Sea. Bioinvasions Rec 1:53-57

Bariche M, Azzurro E (2012) New records and establishment of the Indian Ocean two spot cardinalfish Cheilodipterus novemstriatus (Rüppell, 1838) in the Mediterranean Sea. Bioinvasions Rec 1:299-301

Bariche M, Bernardi G (2009) Lack of a genetic bottleneck in a recent Lessepsian bioinvader, the blue-barred parrotfish, Scarus ghobban. Mol Phylogenet Evol 53:592-595

Bariche M, Heemstra P (2012) First record of the blackstrip grouper Epinephelus fasciatus (Teleostei: Serranidae) in the Mediterranean Sea. Mar Biodivers Rec 5:1-3

Bariche M, Bilecenoğlu M, Azzurro E (2013) Confirmed presence of the Red Sea goatfish Parupeneus forsskali (Fourmanoir and Guézé, 1976) in the Mediterranean Sea. Bioinvasions Rec 2:173-175

Baum JK, Worm B (2009) Cascading top-down effects of changing oceanic predator abundance. J Anim Ecol 78:699-714

Belmaker J, Parravicini V, Kulbicki M (2013) Ecological traits and environmental affinity explain Red Sea fish introduction into the Mediterranean. Glob Change Biol 19:1373-1382

Ben Rais Lasram F, Mouillot D (2009) Increasing southern invasion enhances congruence between endemic and exotic Mediterranean fish fauna. Biol Invasions 11:697-711

Ben Rais Lasram F, Tomasini JA, Guilhaumon F, Romdhane MS, Do Chi T, Mouillot D (2008) Ecological correlates of dispersal success of Lessepsian fishes. Mar Ecol Prog Ser 363:273-286

Ben Rais Lasram F, Guilhaumon F, Mouillot D (2010) Global warming and exotic fishes in the Mediterranean Sea: introduction 
dynamic, range expansion and spatial congruence with endemic species. In: Golani D, Appelbaum-Golani B (eds) Fish invasions of the Mediterranean Sea: change and renewal. Pensoft Publishers, Sofia-Moscow, pp 189-217

Ben-Tuvia A, Golani D (1996) Temperature as the main factor influencing Lessepsian migration. In: Benhamida S, Le Goff F (eds) The Mediterranean Sea in the 21st century: Who for? Mediterranean: climatic variability, Environment and Biodiversity. Maison de l'environnement de Montpellier, Montpellier, pp 159-162

Ben-Yami M, Glaser T (1974) The invasion of Saurida undosquamis (Richardson) into the Levant basin: an example of biological effect of interoceanic canals. FISH-B-NOAA 72:359-373

Bilecenoğlu M (2010) Alien marine fishes of Turkey: an updated review. In: Golani D, Appelbaum-Golani B (eds) Fish invasions of the Mediterranean Sea: change and renewal. Pensoft Publishers, Sofia-Moscow, pp 189-217

Bilecenoğlu M (2012) First sighting of the Red Sea originated stonefish (Synanceia verrucosa) from Turkey. J Black Sea/Medit Environ 18:76-82

Bilecenoğlu M, Yokeş MB, Eryigit A (2008) First record of Vanderhorstia mertensi Klausewitz, 1974 (Pisces, Gobiidae) in the Mediterranean. Aquat Invasions 3:487-490

Brammeier J, Polls IS, Mackey S (2008) Preliminary feasibility of ecological separation of the Mississippi River and the Great Lakes to prevent the transfer of aquatic invasive species. Alliance for the Great Lakes, 2008 Project Completion Report, Chicago, pp 1-112

Çiçek E, Bilecenoğlu M (2009) A new alien fish in the Mediterranean Sea: Champsodon nudivittis (Actinopterygii: Perciformes: Champsodontidae). Acta Ichthyol Pisc 39:67-69

Dalyan C, Yemişken E, Eryılmaz L (2012) A new record of gaper (Champsodon capensis Regan, 1908) in the Mediterranean Sea. J Appl Ichthyol 28:834-835

Dawson MN, Waples RS, Bernardi G (2006) Phylogeography. In: Allen LG, Pondella DJ II, Horn MH (eds) The ecology of marine fishes: California and adjacent waters. University of California Press, Berkeley, pp 26-54

Despalatović M, Grubelić I, Nikolić V, Dragičević B, Dulčić J, Žuljević A, Cvitković I, Antolić B (2008) Allochthonous warm water species in the benthic communities and ichthyofauna of the eastern part of the Adriatic Sea. In: Briand F (ed) Climate warming and related changes in Mediterranean marine biota. CIESM Workshop Monographs, No 35, Monaco, pp 51-57

EastMed (2010) Report of the sub-regional technical meeting on the Lessepsian migration and its impact on Eastern Mediterranean fishery. GCP/INT/041/EC-GRE-ITA/TD-04, pp 1-140

Edelist D, Golani D, Rilov G, Spanier E (2012) The invasive venomous striped eel catfish Plotosus lineatus in the Levant: possible mechanisms facilitating its rapid invasional success. Mar Biol 159:283-290

Figueira WF, Booth DJ (2010) Increasing ocean temperatures allow tropical fishes to survive overwinter in temperate waters. Glob Change Biol 16:506-516

Fricke R, Golani D, Appelbaum-Golani B (2012) First record of the Indian Ocean anchovy Stolephorus insularis Hardenberg, 1933 (Clupeiformes: Engraulidae) in the Mediterranean. Bioinvasions Rec 1:303-306

Froese R, Pauly D (eds) (2014) Fish Base. World Wide Web electronic publication, version 08/2014. www.fishbase.org. Last Accessed 21 Jan 2015

Galil BS (2006) The Suez Canal. In: Gollasch S, Galil BS, Cohen AN (eds) Bridging divides: maritime canals as invasion corridors. Springer, Dordrecht, pp 207-300

Galil BS, Boero F, Campbell ML et al (2015) 'Double trouble': the expansion of the Suez Canal and marine bioinvasions in the Mediterranean Sea. Biol Invasions 17:973-976
Golani D (1993) The sandy shore of the Red Sea: launching pad for Lessepsian (Suez Canal) migrant fish colonizers of the eastern Mediterranean. J Biogeogr 20:579-585

Golani D (1998) Impact of Red Sea fish migrants through the Suez Canal on the aquatic environment of the eastern Mediterranean. Yale Sch For Environ Stud Bull 103:375-387

Golani D (2004) First record of the muzzled blenny (Osteichthyes: Blenniidae: Omobranchus punctatus) from the Mediterranean, with remarks on ship-mediated fish introduction. J Mar Biol Assoc UK 84:851-852

Golani D (2010) Colonization of the Mediterranean by Red Sea fishes via the Suez Canal: Lessepsian migration. In: Golani D, Appelbaum-Golani B (eds) Fish invasions of the Mediterranean Sea: change and renewal. Pensoft Publishers, Sofia-Moscow, pp 145-188

Golani D, Appelbaum-Golani B (eds) (2010a) Fish invasions of the Mediterranean Sea: change and renewal. Pensoft, Sofia-Moscow

Golani D, Appelbaum-Golani B (2010b) First record of the IndoPacific fish the Jarbua terapon (Terapon jarbua) (Osteichthyes: Terapontidae) in the Mediterranean with remarks on the wide geographical distribution of this species. Sci Mar 74:717-720

Golani D, Azzurro E, Corsini-Foka M, Falautano M, Andaloro F, Bernardi G (2007) Genetic bottlenecks and successful biological invasions: the case of a recent Lessepsian migrant. Biol Lett 3:541-545

Golani D, Salameh P, Sonin O (2010) First record of the emperor angelfish, Pomacanthus imperator (Teleostei: Pomacanthidae) and the second record of the spotbase burrfish Cyclichthys spilostylus (Teleostei: Diodontidae) in the Mediterranean. Aquat Invasions 5(Suppl 1):41-43

Golani D, Fricke R, Appelbaum-Golani B (2011) First record of the Indo-Pacific slender ponyfish Equulites elongatus (Günther, 1874) (Perciformes: Leiognathidae) in the Mediterranean. Aquat Invasions 6(Suppl 1):75-77

Golani D, Orsi-Relini L, Massutí E, Quignard JP, Dulčić J, Azzurro E (2013) CIESM Atlas of Exotic Species in the Mediterranean. Version 2013. www.ciesm.org/atlas/appendix1.html. Last Accessed 21 Jan 2015

Gollasch S, Galil BS, Cohen AN (eds) (2006) Bridging divides: maritime canals as invasion corridors. Springer, Dordrecht

González-Irusta JM, Punzón A, Serrano A (2012) Environmental and fisheries effects on Gracilechinus acutus (Echinodermata: Echinoidea) distribution: Is it a suitable bioindicator of trawling disturbance? ICES J Mar Sci. doi:10.1093/icesjms/fss102

Goren M, Galil BS (2005) A review of changes in the fish assemblages of Levantine inland and marine ecosystems following the introduction of non-native fishes. J Appl Ichthyol 21:364-370

Goren M, Lipsky G, Brokovich E, Abelson A (2010a) A 'flood' of alien cardinal fishes in the eastern Mediterranean: first record of the Indo-Pacific Cheilodipterus novemstriatus (Rüppell, 1838) in the Mediterranean Sea. Aquat Invasions 5(Suppl 1):49-51

Goren M, Stern N, Galil BS, Diamant A (2010b) First record of the Indo-Pacific arrow bulleye Priacanthus sagittarius Starnes, 1988 in the Mediterranean. Aquat Invasions 5(Suppl 1):45-47

Goren M, Gvili R, Galil BS (2011) The reef-associating butterfly fish Chaetodon austriacus Rüppell, 1836 in the Mediterranean: the implication of behavioural plasticity for bioinvasion hazard assessment. Aquat Invasions 6(Suppl 1):143-145

Gücü AC, Ok M, Sakınan S (2010) Past and present of fish fauna in the NE Levant Sea and factor facilitating the colonization by Lessepsian fishes. In: EastMed (2010) Report of the SubRegional Technical meeting on the Lessepsian migration and its impact on Eastern Mediterranean fishery. GCP/INT/041/ECGRE-ITA/TD-04, pp 88-110

Haas G (2002) Entwicklung der Makroinvertebraten-Gemeinschaft im hessischen Rhein- und Untermainabschnitt in den Jahren 
1993-1999. Hessisches Landesamt für Umwelt und Geologie, Wiesbaden, pp 1-176

Hassan M, Bonhomme F (2005) No reduction in neutral variability of mitochondrial and nuclear genes for a Lessepsian migrant, Upeneus moluccensis. J Fish Biol 66:865-870

Hassan M, Harmelin-Vivien M, Bonhomme F (2003) Lessepsian invasion without bottleneck: example of two rabbitfish species (Siganus rivulatus and Siganus luridus). J Exp Mar Biol Ecol 291:219-232

Jennings S, Kaiser MJ (1998) The effects of fishing on marine ecosystems. Adv Mar Biol 34:201-352

Jennings S, Kaiser MJ, Reynolds JD (2001) Marine fisheries ecology. Blackwell Science, Oxford

Kolar CS, Lodge DM (2002) Ecological predictions and risk assessment for alien fishes in North America. Science 298:1233-1236

Leppäkoski E, Gollasch S, Olenin S (eds) (2002) Invasive aquatic species of Europe: distribution, impacts and management. Kluwer Academic Publishers, Dordrecht

Lester S, Ruttenberg B (2005) The relationship between pelagic larval duration and range size in tropical reef fishes: a synthetic analysis. P Roy Soc B-Biol Sci 272:585-591

Locarnini RA, Mishonov AV, Antonov JI et al (2013) World Ocean Atlas 2013, Volume 1: Temperature. In: Levitus S (ed), Mishonov A (Technical ed) NOAA Atlas NESDIS 73

Lundberg B, Golani D (1995) Diet adaptations of Lessepsian migrant rabbitfishes, Siganus luridus and S. rivulatus, to the algal resources of the Mediterranean coast of Israel. Mar Ecol 16:73-89

Macpherson E, Hastings PA, Robertson DR (2009) Macroecological patterns among marine fishes. In: Witman JD, Roy K (eds) Marine macroecology. University of Chicago Press, Chicago, pp 122-152

Marchetti MP, Moyle PB, Levine R (2004) Alien fishes in California watersheds: characteristics of successful and failed invaders. Ecol Appl 14:587-596

Mariotti A, Pan Y, Zeng N, Alessandri A (2015) Long-term climate change in the Mediterranean region in the midst of decadal variability. Clim Dyn 44:1437-1456

McCullagh P, Nelder JA (1989) Generalized linear models, 2nd edn. Chapman \& Hall, London

Mills EL, Leach JH, Carlton JT, Secor CL (1993) Exotic species in the Great Lakes: a history of biotic crises and anthropogenic introductions. J Great Lakes Res 19:1-54

Mora C, Robertson DR (2005) Factors shaping the range-size frequency distribution of the endemic fish fauna of the Tropical Eastern Pacific. J Biogeogr 32:277-286

Moyle PB, Marchetti MP (2006) Predicting invasion success: freshwater fishes in California as a model. Bioscience 56:515-524

Nentwig W (ed) (2007) Biological invasions. Ecological studies 193. Springer, Berlin, Heidelberg

Norman JR (1927) Zoological results of the Cambridge expedition to the Suez Canal, 1924. XXV. Report on the fishes. Trans Zool Soc Lond 22:375-390

Norman JR (1929) Notes on the fishes of the Suez Canal. Proc Zool Soc Lond 2:615-616

OBIS (2015) Data from the Ocean Biogeographic Information System. Intergovernmental Oceanographic Commission of UNESCO. http://www.iobis.org. Last Accessed 21 Jan 2015

Occhipinti-Ambrogi A (2007) Global change and marine communities: alien species and climate change. Mar Poll Bull 55:342-352

Occhipinti-Ambrogi A, Galil B (2010) Marine alien species as an aspect of global change. Adv Oceanogr Limnol 1:199-218

Orsi Relini L (1990) Synagrops japonicus (Steindachner e Doderlein, 1884) (Pisces, Acropomatidae) nel Mediterraneo: un migrante lessepsiano? Oebalia 16:217-223
Otero M, Cebrian E, Francour P, Galil B, Savini D (2013) Monitoring marine invasive species in Mediterranean marine protected areas (MPAs): a strategy and practical guide for managers. IUCN, Malaga

Özgür Özbek E, Özkaya M, Öztürk B, Golani D (2014) First record of the blenny Parablennius thysanius (Jordan and Seale, 1907) in the Mediterranean. J Black Sea/Med Env 20:53-59

Özvarol Y, Gökoğlu M (2012) First record of the Indo-Pacific milkfish Chanos chanos (Forskål, 1775) (sic.) in the Turkish Mediterranean Sea. Zool Middle East 55:135-136

Pallaoro A, Dulčić J (2001) First record of the Sphyraena chrysotaenia (Klunzinger, 1884) (Pisces, Sphyraenidae) from the Adriatic Sea. J Fish Biol 59:179-182

Perry AL, Low PJ, Ellis JR, Reynolds JD (2005) Climate change and distribution shifts in marine fishes. Science 308:1912-1915

Pörtner HO, Peck MA (2010) Climate change effects on fishes and fisheries: towards a cause-and-effect understanding. J Fish Biol 77:1745-1779

Raitsos DE, Beaugrand G, Georgopoulos D, Zenetos A, PancucciPapadopoulou AM, Theocharis A, Papathanassiou E (2010) Global climate change amplifies the entry of tropical species into the Eastern Mediterranean Sea. Limnol Oceanogr 55:1478-1484

Rilov G, Galil B (2009) Marine bioinvasions in the Mediterranean Sea: history, distribution and ecology. In: Rilov G, Crooks JA (eds) Biological invasions in marine ecosystems. Springer, Berlin, pp 549-575

Roessig JM, Woodley CM, Cech JJ, Hansen LJ (2004) Effects of global climate change on marine and estuarine fishes and fisheries. Rev Fish Biol Fisher 14:251-275

Safriel UN, Ritte U (1980) Criteria for the identification of potential colonizers. Biol J Linn Soc 13:287-297

Salameh P, Sonin O, Golani D (2010) First record of the burrowing goby, Trypauchen vagina (Bloch and Schneider, 1801) (Teleostei: Gobiidae: Amblyopinae) in the Mediterranean. Acta Ichthyol Pisc 40:109-111

Salameh P, Sonin O, Edelist D, Golani D (2011) First record of the Red Sea orangeface butterflyfish Chaetodon larvatus Cuvier, 1831 in the Mediterranean. Aquat Invasions 6(Suppl 1):53-55

Salameh P, Sonin O, Edelist D, Golani D (2012) The first substantiated record of the yellowbar angelfish, Pomacanthus maculosus (Perciformes, Pomacanthidae) in the Mediterranean. Acta Ichthyol Pisc 42:73-74

Schembri PJ, Tonna R (2011) Occurrence of the Malabar grouper Epinephelus malabaricus (Bloch and Schneider, 1801) (Actinopterygii, Perciformes, Serranidae), in the Maltese Islands. Aquat Invasions 6(Suppl 1):129-132

Schembri P, Bodilis P, Evans J, Francour P (2010) Occurrence of barred knifejaw, Oplegnathus fasciatus (Actinopterygii: Perciformes: Oplegnathidae), in Malta (Central Mediterranean) with a discussion on possible modes of entry. Acta Ichthyol Pisc 40:101-104

Steinitz W (1927) Beiträge zur Kenntnis der Küstenfauna Palästinas. I Publ Staz Zool Napoli 8:311-353

Stern N, Goren M (2013) First record of the moray eel Gymnothorax reticularis, Bloch, 1795 in the Mediterranean Sea, with a note on its taxonomy and distribution. Zootaxa 3641:197-200

Strona G, Galli P, Montano S, Seveso D, Fattorini S (2012) Globalscale relationships between colonization ability and range size in marine and freshwater fish. PLoS ONE. doi:10.1371/journal. pone. 0049465

Suez Canal authority (2015) Canal Characteristics. www.suezcanal. gov.eg/sc.aspx? show=12. Accessed 18 Feb 2015

Tillier J-B (1902) Le Canal de Suez et sa fauna ichthyologique. Mém Soc zool Fr 15:279-318 
Tittensor D, Worm B, Myers RA (2009) Macroecological changes in exploited marine systems. In: Witman JD, Roy K (eds) Marine macroecology. University of Chicago Press, Chicago, pp 310-337

Tittizer T, Schöll F, Banning M, Haybach A, Schleuter M (2000) Aquatische Neozoen im Makrozoobenthos der Binnenwasserstraßen Deutschlands. Lauterbornia Dinkelscherben 39:1-72

Verges A, Tomas F, Cebrian E, Ballesteros E, Kizilkaya Z, Dendrinos P, Karamanlidis AA, Spiegel D, Sala E (2014) Tropical rabbitfish and the deforestation of a warming temperate sea. J Ecol 102:1518-1527
Wellington GM, Victor BC (1989) Planktonic larval duration of one hundred species of Pacific and Atlantic damselfishes (Pomacentridae). Mar Biol 101:557-567

Yağlıoğlu D, Turan C (2012) Colonization and genetic changes of Indo-Pacific immigrant Saurida undosquamis (Richardson, 1948) (lizardfish) in the Mediterranean Sea. J Black Sea/Medit Environ 18:329-340

Zammit E, Schembri PJ (2011) An overlooked and unexpected introduction? Occurrence of the spotted scat Scatophagus argus (Linnaeus, 1766) (Osteichthyes: Scatophagidae) in the Maltese Islands. Aquat Invasions 6(Suppl 1):79-83 